\title{
Minimal and extended hammerheads utilize a similar dynamic reaction mechanism for catalysis
}

\author{
JENNIFER A. NELSON and OLKE C. UHLENBECK \\ Department of Biochemistry, Molecular Biology and Cell Biology, Northwestern University, Evanston, Illinois 60208, USA
}

\begin{abstract}
Analysis of the catalytic activity of identical mutations in the catalytic cores of nHH8, a very active "extended" hammerhead, and HH16, a less active "minimal" hammerhead, reveal that the tertiary Watson-Crick base pair between C3 and G8 seen in the recent structure of the Schistosoma mansoni extended hammerhead can be replaced by other base pairs in both backgrounds. This supports the model that both hammerheads utilize a similar catalytic mechanism but HH16 is slower because it infrequently samples the active conformation. The relative effect of different mutations at positions 3 and 8 also depends on the identity of residue 17 in both $\mathrm{nHH} 8$ and $\mathrm{HH} 16$. This synergistic effect can best be explained by transient pairing between residues 3 and 17 and 8 and 13, which stabilize an inactive conformation. Thus, mutants of nHH8 and possibly nHH8 itself are also in dynamic equilibrium with an inactive conformation that may resemble the $\mathrm{X}$-ray structure of a minimal hammerhead. Therefore, both minimal and extended hammerhead structures must be considered to fully understand hammerhead catalysis.
\end{abstract}

Keywords: ribozyme; catalytic RNA; conformational change

\section{INTRODUCTION}

The hammerhead ribozyme was originally defined as an RNA self-cleaving motif consisting of three helices intersecting at a catalytic core of 13 single-stranded conserved residues (Buzayan et al. 1986; Hutchins et al. 1986; Forster and Symons 1987a,b; Uhlenbeck 1987). Such a "minimal" hammerhead cleaves efficiently at a unique site at a rate of $\sim 1 \mathrm{~min}^{-1}$ at $25^{\circ} \mathrm{C}$ in neutral buffers containing $10 \mathrm{mM}$ magnesium ions (Hertel et al. 1994; Stage-Zimmermann and Uhlenbeck 1998). Several X-ray crystal structures of minimal hammerheads show that the three helices adopt an overall Y shape with the adjoining catalytic core consisting of two distinct domains (Pley et al. 1994; Scott et al. 1995, 1996; Murray et al. 2000). However, the structures did not suggest an obvious catalytic mechanism and could not explain a substantial amount of biochemical data on modified hammerheads (McKay 1996; Verma et al. 1997; Blount and Uhlenbeck 2005). It was subsequently found that natural hammerheads contain nonconserved hairpin loops or internal loops within helices I and II that form a

Reprint requests to: Okle C. Uhlenbeck, Department of Biochemistry, Molecular Biology and Cell Biology, Northwestern University, 2205 Tech Drive, Hogan 2-100, Evanston, IL 60208, USA; e-mail: o-uhlenbeck@ northwestern.edu; fax: (847) 491-5444.

Article published online ahead of print. Article and publication date are at http://www.rnajournal.org/cgi/doi/10.1261/rna.717908. tertiary interaction (De la Pena et al. 2003; Khvorova et al. 2003). Such "extended" hammerheads show rate constants that are at least 100-fold faster than minimal hammerheads under comparable reaction conditions (De la Pena et al. 2003; Khvorova et al. 2003; Canny et al. 2004; Nelson et al. 2005; Roychowdhury-Saha and Burke 2006; Canny et al. 2007). A recent crystal structure of an extended hammerhead from Schistosoma mansoni confirmed the presence of the tertiary interaction and revealed a structure of the catalytic core that is substantially different from the arrangement of the core within the minimal hammerhead structures (Martick and Scott 2006). Instead of folding into the two separate domains present in the minimal hammerhead structure, the entire catalytic core of the extended hammerhead folds into a single unit with the scissile phosphodiester bond lying adjacent to potential catalytic residues. In addition, although activity in the $\mathrm{X}$-ray structure is blocked by the presence of a $2^{\prime}$-O-methyl group, the positions of the $2^{\prime}$ oxygen, the scissile phosphate, and the $5^{\prime}$ oxygen are nearly aligned for the expected in-line attack. Thus, the extended hammerhead has a structure that seems close to the known transition state required by the $\mathrm{S}_{\mathrm{N}} 2(\mathrm{P})$ mechanism (van Tol et al. 1990; Koizumi and Ohtsuka 1991; Slim and Gait 1991), providing a convincing rationale for the faster observed rate.

Despite lacking the rate enhancing tertiary interaction and possessing a quite different core structure, the minimal 
hammerhead is actually a rather effective ribozyme, cleaving at a rate of $\sim 10^{6}$-fold faster than the average uncatalyzed rate of phosphodiester bond cleavage (Hertel et al. 1997; Li and Breaker 1999; Soukup and Breaker 1999). Since the extended hammerheads cleave only several hundred-fold faster, it is clear that the minimal hammerhead still possesses at least two thirds of the catalytic rate enhancement associated with hammerhead catalysis. Two possible explanations for the activity of the minimal hammerhead have been proposed. In the first, the minimal hammerhead utilizes a mechanism involving relatively small structural rearrangements around the cleavage site to achieve a configuration appropriate for in-line attack. This suggestion, originally made by Pley et al. (1994), was supported by a series of structures of derivatives of a minimal hammerhead, including ones with and without bound magnesium ions, a talo-5' -C-methyl modification at the cleavage site, and a product complex (Scott et al. 1996; Murray et al. 1998, 2000). By ordering these structures in progressively greater in-line arrangement about the scissile phosphate, the potential reaction path earlier proposed was supported (Scott et al. 1996; Murray et al. 1998). A second possibility, suggested by Peracchi et al. (1997, 1998), is that the core of the minimal hammerhead exists in multiple conformations and only infrequently adopts an active conformation that is substantially different from the minimal structure. Subsequent cadmium ion "rescue" experiments of minimal hammerheads containing phosphorothioates (Wang et al. 1999) suggested that the transition state structure involved close approach of phosphates 9 and 1.1 , which are distant in the minimal structures. The juxtaposition of these two phosphates observed in the Schistosoma structure clearly supports this isomerization model for the minimal hammerhead, but additional biochemical experiments are needed to confirm it.

In this article, we compare the effect on catalysis for an identical set of mutations made in the catalytic cores of well characterized minimal and extended hammerheads. The mutations were designed to test the importance of the tertiary Watson-Crick base pair between C3 and G8 that is present in the extended, but not in the minimal, hammerhead structure. In addition, position 17 was mutated, since it interacts with C3 in the minimal hammerhead structure. If both hammerheads show a similar requirement for the C3-G8 base pair, the data would imply that they have a similar transition state structure. This would support the model that the minimal hammerhead rapidly samples multiple conformations and is only catalytically active when it adopts a conformation that resembles the Schistosoma core structure.

\section{RESULTS}

Mutagenesis focused on three positions within the core of the hammerhead ribozyme: the completely conserved residues $\mathrm{C} 3$ and $\mathrm{G} 8$ and the more variable cleavage site nucleotide, N17, which is commonly a C or an A, occasionally a U, and never a G (Garrett et al. 1996; Flores et al. 2001; Carbonell et al. 2006). In the extended hammerhead structure (Fig. 1A), C3 and G8 form a Watson-Crick tertiary base pair that stacks between the terminal G2.1C1.1 base pair of helix I and uridine 7, while C17 is near G12, A13, and A14 (Martick and Scott 2006). In the minimal hammerhead structure (Fig. 1C), G8 forms a sheared base pair with A13 and both stack between the G12-A9 and A14-U7 pairs within domain 2, while C3 forms a single hydrogen bond with $\mathrm{C} 17$ and the two residues stack between the G2.1-C1.1 pair and uridine 4 in domain 1. Previous mutagenesis experiments in minimal hammerheads established that point mutations of either C3 or G8 greatly reduced cleavage, and double mutants between these positions were never tested (Ruffner et al. 1990; Tuschl et al. 1993; Murray et al. 1995; Peracchi et al. 1996; Kore et al. 2000). Mutations of position 17 made in several minimal hammerheads were active in the order $\mathrm{C} 17>\mathrm{A} 17>\mathrm{U} 17$ (Koizumi et al. 1988a; Baidya and Uhlenbeck 1997), while G17 was inactive unless additional mutations were made elsewhere in the catalytic core (Koizumi and Ohtsuka 1991; Vaish et al. 1998; Kore et al. 2000; Eckstein et al. 2001). Experiments with double mutants suggest that strong N3-N17 pairs were deleterious to cleavage (Koizumi and Ohtsuka 1991; Baidya et al. 1997; Baidya and Uhlenbeck 1997). A limited mutagenesis of the C3-G8 pair in the Schistosoma hammerhead revealed that while the G3 single mutant showed dramatically reduced cleavage, the G3C8 double mutation partially restored activity, supporting the new structure (Martick and Scott 2006). Mutagenesis of C3 and G8 to other base pairs in the Arabidopsis and PLMVd hammerheads have recently also confirmed the presence of this base pair (Przybilski and Hammann 2007).

Two kinetically well-characterized hammerheads were chosen for mutagenesis studies. The minimal HH16 (Fig. 1D) has previously been studied extensively (Hertel et al. 1994), while the extended nHH8 (Fig. 1B) is a derivative of the hammerhead in the plus strand of the satellite of lucerne transient streak virus $[\operatorname{sLTSV}(+)]$, which contains a lengthened helix III to permit stable binding. Since hammerhead catalysis involves the transesterfication of an internucleotide phosphodiester bond to a 2', 3' cyclic phosphate product, the reaction is fully reversible and is expected to show the same apparent rate constant $\left(k_{\mathrm{obs}}\right)$ and reach the same fraction of uncleaved molecules at equilibrium $\left(f_{\text {eq }}\right)$ when the assay is performed using the forward, cleavage reaction or the reverse, ligation reaction. $\mathrm{HH} 16$ is usually assayed in a cleavage reaction where the ribozyme and substrate strands are annealed and the reaction is started by addition of $\mathrm{MgCl}_{2}$. At $10 \mathrm{mM} \mathrm{MgCl}$ ( $\mathrm{pH}$ 7.5), cleavage kinetics of HH16 follows a single exponential with a $k_{\text {obs }}=0.7 \mathrm{~min}^{-1}$ and $f_{\text {eq }}=0.15$ (Hertel 
A

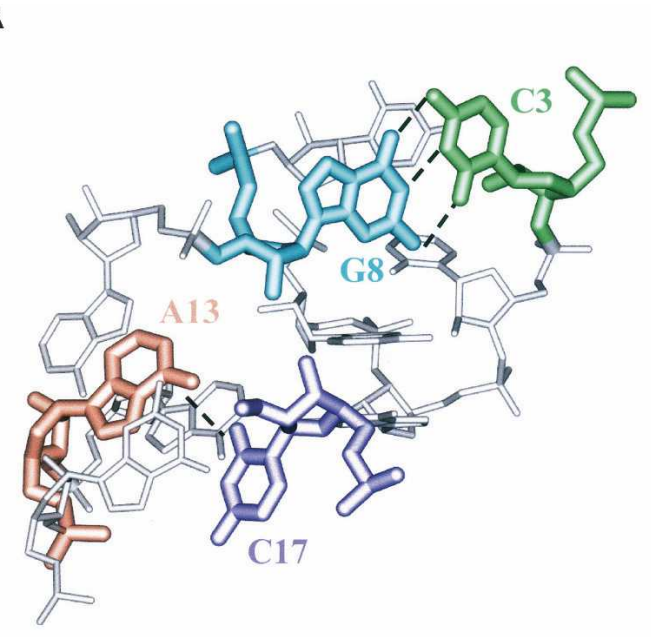

C

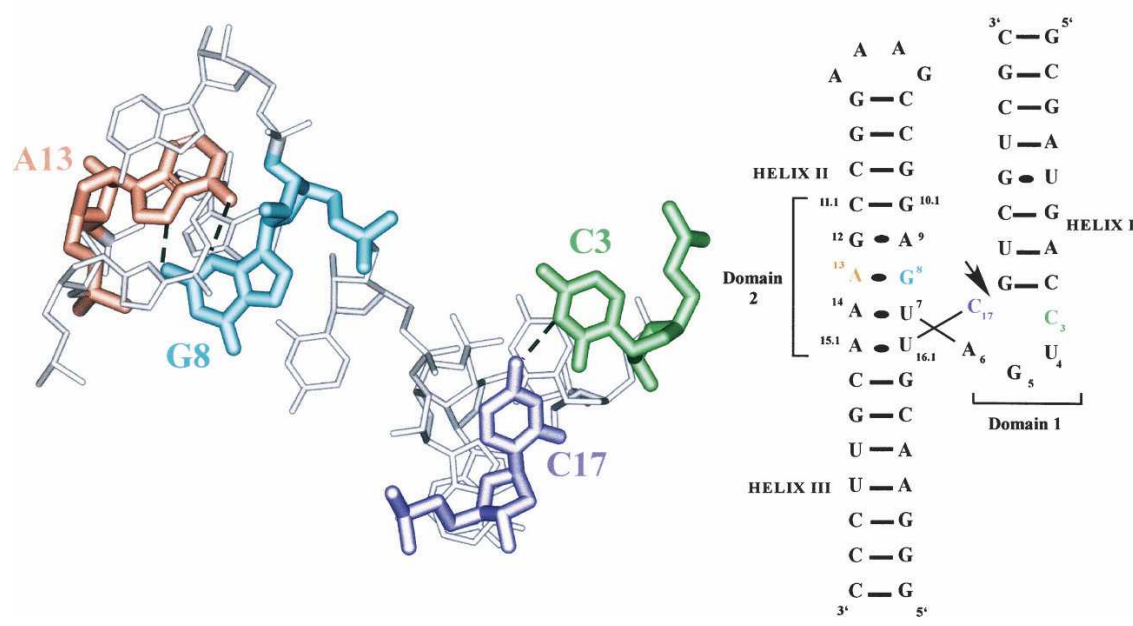

FIGURE 1. The tertiary and secondary structures of extended and minimal hammerheads. Critical core nucleotides include: C17 (purple), C3 (green), G8 (blue), and A13 (orange). (A) The four nucleotides as they are arranged in the crystal structure of the catalytic core of a noncleavable extended hammerhead from Schistosoma (PDB 2GOZ) (Martick and Scott 2006). (B) Secondary structure of nHH8 derived from sLTSV(+) with the core arranged to reflect the crystal structure. $(C)$ The four nucleotides arranged in the catalytic core of a noncleavable minimal hammerhead (PDB 1HMH) (Pley et al. 1994). (D) The secondary structure of the minimal HH16 (Hertel et al. 1994) with a core arranged in the two distinct domains seen in the X-ray structure.

et al. 1994). When HH16 is assayed in a ligation reaction under the same conditions, $k_{\mathrm{obs}}=0.95 \mathrm{~min}^{-1}$ and $f_{\mathrm{eq}}=$ 0.008 (Hertel et al. 1994). Thus, although the two assays give similar $k_{\text {obs }}$ values as expected, the disparity in the $f_{\text {eq }}$ data suggests that one of the reactions may contain a fraction of catalytically inactive molecules. Since $f_{\text {eq }}$ in the cleavage reaction can be reduced to less than 0.1 by treatment of HH16 with chaperones (Herschlag et al. 1994), it appears that a fraction of the uncleaved HH16 molecules are in a misfolded, inactive conformation that does not become active during the time course of the cleavage reaction.
The activity of $\mathrm{nHH} 8$ is generally assayed in a ligation reaction by annealing the two product fragments and starting the reaction by the addition of $\mathrm{MgCl}_{2}$ (Nelson et al. 2005). At $1 \mathrm{mM}$ $\mathrm{MgCl}_{2}$ ( $\mathrm{pH}$ 6.0), a single exponential rate of ligation is observed with a $k_{\mathrm{obs}}=$ $2.5 \mathrm{~min}^{-1}$ and $f_{\mathrm{eq}}=0.052$ (Table 1 ). In $10 \mathrm{mM} \mathrm{MgCl}_{2}$ (pH 7.5), $k_{\text {obs }}$ is a much faster $470 \mathrm{~min}^{-1}$ (I. Shepotinovskaya, unpubl.). Determining $k_{\mathrm{obs}}$ for $\mathrm{nHH} 8$ using a cleavage assay is technically challenging because the full-length hammerhead must be purified from a transcription reaction containing an inhibitory complementary DNA fragment and then re-annealed in a buffer without $\mathrm{MgCl}_{2}$, a process that often yields partially cleaved molecules (Nelson et al. 2005). Cleavage reactions are then initiated by the addition of $\mathrm{MgCl}_{2}$. At 1 $\mathrm{mM} \mathrm{MgCl}_{2}$ (pH 6.0), the cleavage assay gave values of $k_{\mathrm{obs}}=3.2 \mathrm{~min}^{-1}$ and $f_{\mathrm{eq}}=$ 0.05 for $\mathrm{nHH} 8$ (I. Shepotinovskaya, unpubl.). While the cleavage data are less reliable, the close agreement of both $k_{\text {obs }}$ and $f_{\text {eq }}$ in the two assays suggests that, unlike HH16, nHH8 contains relatively few inactive molecules.

The activity of nHH8 and the G3, C8, G3C8, A3U8, and U3A8 mutations was determined in ligation reactions where the 51-nucleotide (nt) ribozymes were each combined with a $\left[5^{\prime}-\mathrm{P}^{32}\right]$-labeled 9-nt product containing $\mathrm{C} 17$ and the rate determined in $1 \mathrm{mM} \mathrm{MgCl}_{2}(\mathrm{pH}$ 6.0). An individual set of rate determinations is shown in Figure 2A. For the wild-type C3G8 and the three other N3N8 mutants, values of $f_{\mathrm{eq}}$ and $k_{\mathrm{obs}}$ could be obtained by fitting the data to a single exponential. Average $f_{\mathrm{eq}}$ and $k_{\text {obs }}$ values from multiple determinations are summarized in Table 1.

The G3 and C8 single mutations ligated so slowly that it was not possible to approach completion in the $1 \mathrm{mM}$ $\mathrm{MgCl}_{2}$ (pH 6.0) buffer even after several days of incubation. Instead, reactions were performed at $10 \mathrm{mM} \mathrm{MgCl}_{2}(\mathrm{pH}$ 7.5 ), where the reaction rate was fast enough that values of $f_{\text {eq }}$ could be extrapolated from data collected over $30 \mathrm{~h}$ and $k_{\text {obs }}$ values calculated (Fig. $2 \mathrm{~A}$, inset). If it is assumed that the two point mutations show a similar dependence of $k_{\mathrm{obs}}$ on $\mathrm{pH}$ and magnesium ion concentration as wild type, these values of $k_{\text {obs }}$ should be divided by a factor of 3200 to estimate the cleavage rate in the $1 \mathrm{mM} \mathrm{MgCl}_{2}$ ( $\mathrm{pH}$ 6.0) 
TABLE 1. Ligation data for $\mathrm{nHH} 8$

\begin{tabular}{|c|c|c|c|c|}
\hline & & $f_{\text {eq }}$ & $k_{\mathrm{obs}}\left(\min ^{-1}\right)$ & $k_{\mathrm{rel}}{ }^{\mathrm{a}}$ \\
\hline \multicolumn{5}{|c|}{ C17 hammerheads } \\
\hline C3/G8 & 0.052 & \pm 0.01 & $2.5 \pm 1.1$ & 1.0 \\
\hline G3/C8 & 0.16 & \pm 0.06 & $0.017 \pm 0.005$ & $6.8 \times 10^{-3}$ \\
\hline A3/U8 & 0.026 & \pm 0.009 & $2.7 \times 10^{-3} \pm 1.6 \times 10^{-3}$ & $8.8 \times 10^{-4}$ \\
\hline U3/A8 & 0.069 & \pm 0.014 & $0.030 \pm 0.009$ & $1.2 \times 10^{-2}$ \\
\hline \multicolumn{5}{|c|}{ A17 hammerheads } \\
\hline C3/G8 & 0.045 & \pm 0.018 & $0.95 \pm 0.52$ & 1.0 \\
\hline G3/C8 & $9.6 \times 10^{-3}$ & $\pm 2.5 \times 10^{-3}$ & $0.063 \pm 0.017$ & $5.2 \times 10^{-2}$ \\
\hline A3/U8 & 0.046 & \pm 0.021 & $4.0 \times 10^{-4} \pm 1.6 \times 10^{-4}$ & $4.1 \times 10^{-4}$ \\
\hline U3/A8 & 0.33 & \pm 0.06 & $1.6 \times 10^{-3} \pm 2.0 \times 10^{-4}$ & $1.3 \times 10^{-3}$ \\
\hline \multicolumn{5}{|c|}{ U17 hammerheads } \\
\hline C3/G8 & 0.14 & \pm 0.02 & $0.046 \pm 0.014$ & 1.0 \\
\hline G3/C8 & 0.073 & \pm 0.032 & $2.5 \times 10^{-3} \pm 1.7 \times 10^{-3}$ & $5.4 \times 10^{-2}$ \\
\hline A3/U8 & 0.029 & \pm 0.0060 & $9.4 \times 10^{-5} \pm 3.5 \times 10^{-6}$ & $2.0 \times 10^{-3}$ \\
\hline U3/A8 & 0.30 & \pm 0.07 & $2.8 \times 10^{-4} \pm 9.1 \times 10^{-5}$ & $4.8 \times 10^{-3}$ \\
\hline \multicolumn{5}{|c|}{ G17 hammerheads } \\
\hline C3/G8 & 0.042 & \pm 0.016 & $0.78 \pm 0.30$ & 1.0 \\
\hline G3/C8 & 0.027 & \pm 0.008 & $0.012 \pm 0.0046$ & $1.5 \times 10^{-2}$ \\
\hline A3/U8 & & n.d & n.d. & - \\
\hline U3/A8 & 0.28 & \pm 0.07 & $2.3 \times 10^{-3} \pm 1.0 \times 10^{-3}$ & $2.9 \times 10^{-3}$ \\
\hline
\end{tabular}

Data collected in $50 \mathrm{mM}$ Mes (pH 6.0), $1 \mathrm{mM} \mathrm{MgCl}_{2}$, at $25^{\circ} \mathrm{C}$ using the ligation assay. Each value was the average $( \pm \mathrm{SD}$ ) of at least three independent determinations like those shown in Figure 2A. n.d. indicates that although tested, very low activity prevented quantitation.

${ }^{\text {a }} k_{\text {rel }}$ is the value of $k_{\text {obs }}$ for a given 3-8 mutation divided by the wild-type $k_{\text {obs }}$ in a given N17 background. buffer (see Materials and Methods). These calculated values are $k_{\mathrm{obs}}=8.2 \times 10^{-7} \mathrm{~min}^{-1}$ for the C8 mutations and $k_{\mathrm{obs}}$ $=1.6 \times 10^{-6} \mathrm{~min}^{-1}$ for the G8 mutations, but as extrapolations, the values should only be considered estimates.

In agreement with similar experiments done on the Schistosoma hammerhead (Martick and Scott 2006) and the Arabidopsis and PLMVd hammerheads (Przybilski and Hammann 2007), the experiments on $\mathrm{nHH} 8$ confirm the presence of the C3-G8 tertiary base pair seen in the Schistosoma crystal structure. The two point mutants G3 and $\mathrm{C} 8$ reduce $k_{\mathrm{obs}}$ by more than six orders of magnitude, which is consistent with the importance of this pair in the folded structure. The double mutant G3C8, which should also be capable of forming a base pair, shows a $k_{\text {obs }} 10,000$ fold faster than the fastest single mutant but remains 150fold slower than nHH8. These results are quantitatively similar for the identical mutations in the Schistosoma hammerhead, where a $k_{\mathrm{obs}}=50 \mathrm{~min}^{-1}$ for the native hammerhead (Canny et al. 2004) is reduced by $\sim 500,000$ fold for the single C8 mutant and 230-fold for the G3C8 double mutant (Martick and Scott 2006). Finally, the A3U8 and U3A8 double mutants of nHH8 both show faster $k_{\mathrm{obs}}$ than the G3 or C8 single mutants, suggesting that they also form a tertiary base pair. Interestingly, the U3A8 derivative has a slightly faster $k_{\text {obs }}$ than the potentially more stable G3C8 mutant. However, it is striking that none of the double mutants come close to restoring the activity to that of the wild-type C3-G8 pair.
Similar to what has been observed for the Schistosoma hammerhead (Canny et al. 2007) and another extended hammerhead (Nelson et al. 2005), the value of $f_{\text {eq }}=0.052$ determined by the ligation reaction is significantly greater than the value of $f_{\text {eq }}=0.008$ for the minimal HH16 ligation reaction. An interesting feature of the data in Figure 2A is that each N3-N8 pair shows a different $f_{\text {eq }}$, including a $f_{\mathrm{eq}}=0.16$ for the G3C8 mutation that is greater than wild type and a $f_{\text {eq }}=0.026$ for the A3U8 mutations that is much less than wild type. These differences do not correlate with the value of $k_{\text {obs }}$ and thus reflect some independent property of each mutation.

The same series of five nHH8 mutations at positions 3 and 8 were then assayed with substrates containing A17, $\mathrm{U} 17$, or G17 in a manner similar to Figure 2A. In each case, $k_{\mathrm{obs}}$ of the $\mathrm{C} 3$ and G8 single mutations was very slow, permitting only estimates of $k_{\mathrm{obs}}$ in the range of $6 \times 10^{-7}-3 \times 10^{-8}$ using data obtained at $10 \mathrm{mM} \mathrm{MgCl}_{2}(\mathrm{pH}$ 7.5) as discussed above. Table 1 reports average $k_{\text {obs }}$ and $f_{\text {eq }}$ values for the four N3-N8 pairs with different residues at N17. It is clear that the identity of N17 affects both $k_{\mathrm{obs}}$ and $f_{\mathrm{eq}}$ in nHH8. The wild-type C17 hammerhead is two- to threefold faster than the A17 and G17 derivatives and 50-fold faster than the U17 derivative. In contrast, $f_{\mathrm{eq}}$ is greatest in the U17 derivative and smallest in the G17 derivative.

The effect of the different mutations at positions 3 and 8 clearly varies with the identity of N17. This is most easily seen by comparing the relative rate constant $\left(k_{\text {rel }}\right)$ of each three to eight mutation with that of the C3G8 wild type in each group of N17 hammerheads (Table 1). The values of $k_{\text {rel }}$ for the three 3-8 base pairs (bp) differ significantly in each N17 set. The most striking effect is that all three of the other N17 hammerheads are much more able to tolerate the G3C8 double mutation than the $\mathrm{C} 17$ hammerhead. Thus, in contrast to the 150 -fold decrease in $k_{\text {obs }}$ determined with the $\mathrm{C} 17$ hammerhead; the U17 hammerhead containing the G3C8 inversion shows a $k_{\text {obs }}$ that is only 20 -fold slower than wild type. Other clear differences in $k_{\text {rel }}$ include the very poor activity of U3A8 mutation in the A17 hammerhead and the somewhat faster $k_{\mathrm{obs}}$ of the A3U8 mutation in the U17 hammerhead. The different combinations of N17 with N3-N8 pairs also show a wide range of $f_{\text {eq }}$ values that do not correlate with either sequence or $k_{\mathrm{obs}}$ value. For example, the G3C8 mutant gives a greater $f_{\text {eq }}$ than wild type with $\mathrm{C} 17$, but it is less with $\mathrm{A} 17$ even though the $k_{\text {rel }}$ for $\mathrm{A} 17$ is greater. 
A

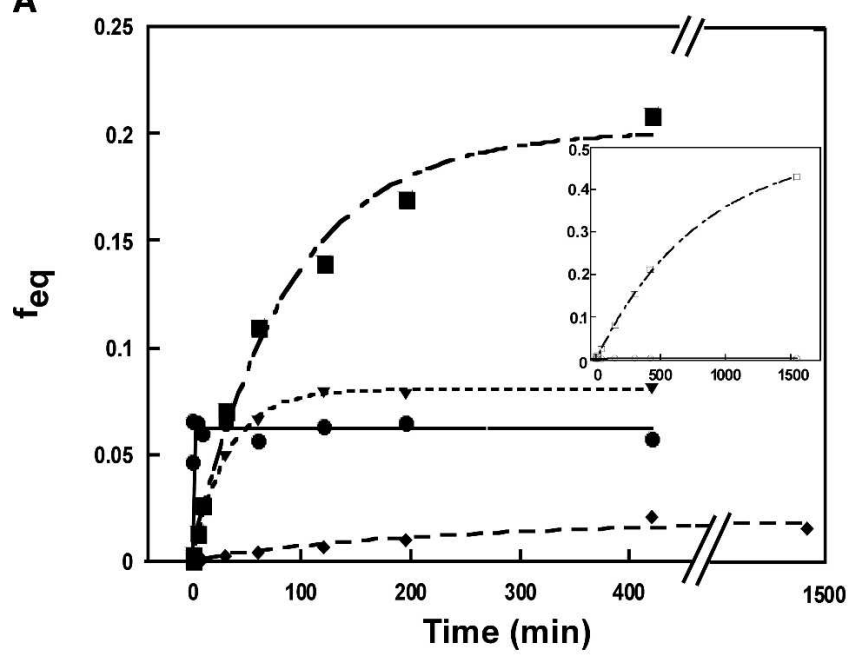

B



FIGURE 2. Rate of approach to equilibrium of nHH8 and $\mathrm{HH} 16$ and their G3, C8, G3C8, A3U8, U3A8 mutations. (A) Single turnover bimolecular ligation reactions for $\mathrm{nHH} 8$ at $1 \mu \mathrm{M}$ ribozyme and trace substrate concentrations at $25^{\circ} \mathrm{C}$ in $50 \mathrm{mM}$ Mes $(\mathrm{pH} 6.0), 1 \mathrm{mM}$ $\mathrm{MgCl}_{2}$ (solid symbols), or $50 \mathrm{mM}$ Hepes (pH 7.5), $10 \mathrm{mM} \mathrm{MgCl}_{2}$ (inset open symbols). Each experiment was fit to a single exponential with a $k_{\mathrm{obs}}$ and $f_{\text {eq }}$, the fraction of full-length product at the end of the reaction. C3G8 wild type $(\bullet) k_{\text {obs }}=3.2 \mathrm{~min}^{-1}, f_{\text {eq }}=0.061$; G3C8 (ם) $k_{\mathrm{obs}}=0.012 \mathrm{~min}^{-1}, f_{\mathrm{eq}}=0.20$; A3U8 $(\diamond) k_{\mathrm{obs}}=0.0037 \mathrm{~min}^{-1}, f_{\mathrm{eq}}=$ 0.018 ; U3A8 $(\boldsymbol{\nabla}) k_{\mathrm{obs}}=0.030 \mathrm{~min}^{-1}, f_{\mathrm{eq}}=0.079 ; \mathrm{C} 8(\square) k_{\mathrm{obs}}=0.0012$ $\min ^{-1}, f_{\text {eq }}=0.45$; and G3 (O) $k_{\text {obs }}=0.0015 \mathrm{~min}^{-1}, k_{\text {obs }}=0.0021$ $\mathrm{min}^{-1}$ in the inset. (B) Single turnover bimolecular cleavage reactions for minimal $\mathrm{HH} 16$ at $25^{\circ} \mathrm{C}$ in $100 \mathrm{mM}$ Hepes (pH 7.5), $10 \mathrm{mM} \mathrm{MgCl}_{2}$ (solid symbols), or $100 \mathrm{mM}$ Tris- $\mathrm{HCl}$ (pH 8.1), $100 \mathrm{mM} \mathrm{MgCl}_{2}$ (open symbols). Experiments fit to a single exponential with $k_{\text {obs }}$ and $f_{\text {eq }}$, the fraction of full-length product at the end of the reaction: C3G8 wild type $(\bullet) k_{\mathrm{obs}}=0.35 \mathrm{~min}^{-1}, f_{\mathrm{eq}}=0.32 ; \mathrm{G} 3 \mathrm{C} 8(\mathbf{\square}) k_{\mathrm{obs}}=0.00037$ $\mathrm{min}^{-1}, f_{\mathrm{eq}}=0.3$; A3U8 $(\diamond) k_{\mathrm{obs}}=0.00083 \mathrm{~min}^{-1}, f_{\mathrm{eq}}=0.18$; U3A8

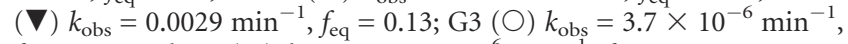
$f_{\text {eq }}=0.3$; and C8 $(\square) k_{\text {obs }}=7.4 \times 10^{-6} \mathrm{~min}^{-1}, f_{\text {eq }}=0.3$.

In order to test whether a minimal hammerhead also shows evidence for a tertiary 3-8 bp, wild-type HH16 and the G3, C8, G3C8, A3U8, and U3A8 mutant ribozymes were assayed in cleavage reactions with the four different
$\left[5^{\prime}-\mathrm{P}^{32}\right]$-labeled, 17-nt substrates containing each N17. Cleavage reactions were chosen instead of ligation reactions in this case because the extent of ligation is too low to permit accurate determination of the slow $k_{\mathrm{obs}}$ values. Figure $2 \mathrm{~B}$ shows a single data set for the $\mathrm{C} 17$ substrate in $10 \mathrm{mM} \mathrm{MgCl} 2$ (pH 7.5). For the wild-type C3G8 hammerhead, rapid cleavage $\left(k_{\mathrm{obs}}=0.50\right)$ to a $f_{\mathrm{eq}}=0.39$ was followed by a much slower component, consistent with very slow conversion of a fraction of inactive molecules to an active state. This confirms previous experiments showing that $\mathrm{HH} 16$ has a fraction of inactive species (Herschlag et al. 1994; Hertel et al. 1994), although the very slow second phase of the reaction had not been reported. Under these conditions, nearly complete progress curves could be obtained for the A3U8 and U3A8 hammerheads after $3000 \mathrm{~min}$, but the G3C8 required $>5000 \mathrm{~min}$ to approach completion. Averages of multiple determinations of $k_{\mathrm{obs}}$ and $f_{\text {eq }}$ values for the four N3N8 mutations are summarized in Table 2.

For the G3 and $\mathrm{C} 8$ single mutations, cleavage was very slow and was incomplete even in $100 \mathrm{mM} \mathrm{MgCl}_{2}$ (pH 8.1) (Fig. 2B, inset). To estimate $k_{\text {obs }}$ values that could be compared with the other data, an $f_{\text {eq }}=0.3$ was assumed and the rates were divided by 40 to account for the higher $\mathrm{pH}$ and $\mathrm{MgCl}_{2}$ concentrations (see Materials and Methods). These estimated values were $k_{\mathrm{obs}}=1.7 \times 10^{-7} \mathrm{~min}^{-1}$ for the C8 mutant and $k_{\text {obs }}=4.2 \times 10^{-7} \mathrm{~min}^{-1}$ for the G3 mutant, which are both similar to estimates of the uncatalyzed rate of RNA cleavage in the same buffer (Hertel et al. 1997; Li and Breaker 1999; Soukup and Breaker 1999).

Corresponding cleavage data for the four N3-N8 derivatives of HH16 were also collected for the A17, U17, and G17 substrates (Table 2). In the case of the A17 and U17 substrates, the much slower cleavage of the N3-N8 mutants made it necessary to estimate an $f_{\text {eq }}$ value to calculate $k_{\text {obs }}$. While these estimates were consistent with values obtained upon very long (10-14 d) incubations (see Materials and Methods), this reduces the accuracy of $k_{\text {obs }}$ and, given that native HH16 contains a significant fraction of inactive species, also prevents interpretation of $f_{\mathrm{eq}}$ data for the different HH16 mutants.

As had been found with other minimal hammerheads (Koizumi et al. 1988b; Ruffner et al. 1990; Koizumi and Ohtsuka 1991; Baidya and Uhlenbeck 1997), the G17 substrates cleaved very poorly even after very long incubation times. However, based upon the relatively robust reactivity of G17 derivatives of $\mathrm{nHH} 8$, we re-evaluated the data and found that HH16(G17) shows biphasic kinetics, with $\sim 4 \%$ of the molecules cleaving with a $k_{\text {obs }}$ $=0.42 \min ^{-1}$ (pH 7.5) at $10 \mathrm{mM} \mathrm{MgCl}$ (Fig. 3A). The remaining molecules cleaved site-specifically but so slowly that the reaction was incomplete after $7000 \mathrm{~min}$ (Fig. 3A, inset). This suggests that the majority of the HH16(G17) molecules were trapped in an inactive structure that is very slowly converted to the active structure. In support of this 
TABLE 2. Cleavage data for HH16

\begin{tabular}{|c|c|c|c|}
\hline & $f_{\text {eq }}$ & $k_{\mathrm{obs}}\left(\min ^{-1}\right)$ & $k_{\text {rel }}{ }^{\mathrm{a}}$ \\
\hline \multicolumn{4}{|c|}{ C17 hammerheads } \\
\hline $\mathrm{C} 3 / \mathrm{G} 8$ & $0.39 \pm 0.08$ & $0.50 \pm 0.16$ & 1.0 \\
\hline $\mathrm{G} 3 / \mathrm{C} 8$ & $0.26 \pm 0.20$ & $3.8 \times 10^{-4} \pm 1.7 \times 10^{-4}$ & $7.6 \times 10^{-4}$ \\
\hline A3/U8 & $0.16 \pm 0.03$ & $7.9 \times 10^{-4} \pm 7.7 \times 10^{-5}$ & $1.6 \times 10^{-3}$ \\
\hline U3/A8 & $0.14 \pm 0.02$ & $3.0 \times 10^{-3} \pm 9.0 \times 10^{-4}$ & $6.0 \times 10^{-3}$ \\
\hline \multicolumn{4}{|c|}{ A17 hammerheads } \\
\hline $\mathrm{C} 3 / \mathrm{G} 8$ & $0.45 \pm 0.07$ & $0.35 \pm 0.15$ & 1.0 \\
\hline $\mathrm{G} 3 / \mathrm{C} 8$ & $0.24 \pm 0.10$ & $1.4 \times 10^{-3} \pm 4.0 \times 10^{-4}$ & $4.0 \times 10^{-3}$ \\
\hline $\mathrm{A} 3 / \mathrm{U} 8$ & [0.30] & $3.5 \times 10^{-4} \pm 1.6 \times 10^{-4}$ & $1.0 \times 10^{-3}$ \\
\hline U3/A8 & [0.30] & $2.0 \times 10^{-4} \pm 9.7 \times 10^{-5}$ & $5.7 \times 10^{-4}$ \\
\hline \multicolumn{4}{|c|}{ U17 hammerheads } \\
\hline C3/G8 & $0.48 \pm 0.03$ & $0.023 \pm 0.011$ & 1.0 \\
\hline $\mathrm{G} 3 / \mathrm{C} 8$ & {$[0.30]$} & $2.5 \times 10^{-4} \pm 1.8 \times 10^{-5}$ & $1.1 \times 10^{-2}$ \\
\hline $\mathrm{A} 3 / \mathrm{U} 8$ & [0.30] & $5.8 \times 10^{-5} \pm 3.4 \times 10^{-5}$ & $2.5 \times 10^{-3}$ \\
\hline U3/A8 & [0.30] & $2.8 \times 10^{-4} \pm 3.4 \times 10^{-5}$ & $1.2 \times 10^{-2}$ \\
\hline \multicolumn{4}{|c|}{ G17 hammerheads } \\
\hline C3/G8 & $0.97 \pm 0.04$ & $0.42 \pm 0.26$ & 1.0 \\
\hline $\mathrm{G} 3 / \mathrm{C} 8$ & $0.94 \pm 0.016$ & $8.7 \times 10^{-4} \pm 4.0 \times 10^{-4}$ & $2.1 \times 10^{-3}$ \\
\hline $\mathrm{A} 3 / \mathrm{U} 8$ & $0.95 \pm 0.010$ & $1.9 \times 10^{-4} \pm 7.4 \times 10^{-5}$ & $4.5 \times 10^{-4}$ \\
\hline U3/A8 & n.d. & n.d. & - \\
\hline
\end{tabular}

Data collected at $100 \mathrm{mM}$ Hepes (pH 7.5), $10 \mathrm{mM} \mathrm{MgCl}_{2}$, at $25^{\circ} \mathrm{C}$ using the cleavage assay. Each value is the average $( \pm \mathrm{SD})$ of at least three independent determinations like those shown in Figure $2 B$. n.d. indicates that although tested, very low activity prevented quantitation. Bracketed values indicate $f_{\text {eq }}$ value assumed to fit data for $k_{\text {obs }}$.

${ }^{a} k_{\text {rel }}$ is the value of $k_{\text {obs }}$ for a given three to eight mutation divided by the wild-type $k_{\text {obs }}$ in a given N17 background. identity of N17. For example, the G3C8 pair is much more effective at replacing the C3-G8 pair with $\mathrm{U} 17$ than with C17 (Table 2).

In general, the response of $\mathrm{HH} 16$ and nHH8 to the same set of mutations is strikingly similar. Figure 4 correlates $k_{\text {obs }}$ in the two hammerhead backgrounds for the 14 mutations from Tables 1 and 2 where accurate $k_{\mathrm{obs}}$ values are available in both cases. Although the different mutations reduce $k_{\text {obs }}$ of each hammerhead by up to four orders of magnitude, their effects are quite comparable in each background. While the two sets of data were obtained under different buffer conditions for experimental convenience, it is unlikely that this will strongly effect the conclusion. To confirm this, $k_{\mathrm{obs}}$ for seven mutations in each hammerhead was measured in the same buffer $(10 \mathrm{mM}$ $\mathrm{MgCl}_{2}$ at $\mathrm{pH} 7.5$ ), and $k_{\text {obs }}$ for a mutation in $\mathrm{nHH} 8$ was consistently faster (35- to 1400-fold) than it was for HH16 (data not shown). The similar effect of different mutations on $k_{\mathrm{obs}}$ in two hammerheads strongly supports the

model, the log of the rate of the fast cleavage component was proportional to $\mathrm{pH}$ as expected for hammerhead cleavage, while the rate of slow component was only slightly affected by $\mathrm{pH}$, more consistent with a conformational change. Furthermore, when HH16(G17) was subjected to multiple rounds of temperature cycling, the extent of cleavage could be increased, which is consistent with a model that a fraction of the inactive complexes becomes active upon incubation at $65^{\circ} \mathrm{C}$ (Fig. 3B). Thus, contrary to previous conclusions, it appears that minimal hammerheads containing G17 are quite active but are primarily trapped in an inactive conformation that only exchanges with the active conformation very slowly. Thus, the $k_{\mathrm{obs}}$ data for the G17 derivatives summarized in Table 2 report only the early phase of the reaction.

The data in Figure 2B and Table 2 clearly establish that a 3-8 bp is also required for HH16 activity. As has previously been observed with other minimal hammerheads (Ruffner et al. 1990; Tuschl et al. 1993; Murray et al. 1995; Peracchi et al. 1996; Kore et al. 2000), both the G3 and C8 point mutations reduce $k_{\mathrm{obs}}$ to a value that approaches the rate for noncatalyzed cleavage of RNA. However all three HH16 mutants that form a base pair between positions 3 and 8 cleave from 34- to 18,000 -fold faster than the point mutations but cleave much slower than the wild-type C3G8 pair. Also similar to nHH8, the ability of the different 3-8 bp to support HH16 cleavage depends upon the tion state.

\section{DISCUSSION}

Mutagenesis experiments establish that the C3-G8 tertiary base pair seen in the crystal structure of the Schistosoma hammerhead is critical for the fast rate of ligation observed in another extended hammerhead derived from $\operatorname{sLTSV}(+)$. The C3 and G8 point mutations that disrupt the pair reduce $k_{\mathrm{obs}}$ six to eight orders of magnitude, consistent with a critical role of the pair for maintaining the folded structure of the hammerhead core. However, nHH8 containing the G3C8 double mutant shows a $k_{\text {obs }}$ considerably faster than the single mutants and, depending on the identity of the residue at position 17 , can have $k_{\text {obs }}$ values within 20-fold of the native C3G8 hammerhead. A3U8 and U3A8 substitutions are also partially active. In agreement with the Schistosoma structure, the role of this tertiary base pair appears to be structural, so other isosteric base pairs can be successfully substituted without eliminating catalytic function.

An important conclusion of this article is that the C3G8 replacement experiments were equally successful in HH16, a slow cleaving "minimal" hammerhead that lacks any tertiary interaction between helices I and II. The C3 and G8 point mutations of $\mathrm{HH} 16$ reduce $k_{\mathrm{obs}}$ to a value that approaches idea that both ribozymes proceed through a similar transi- 

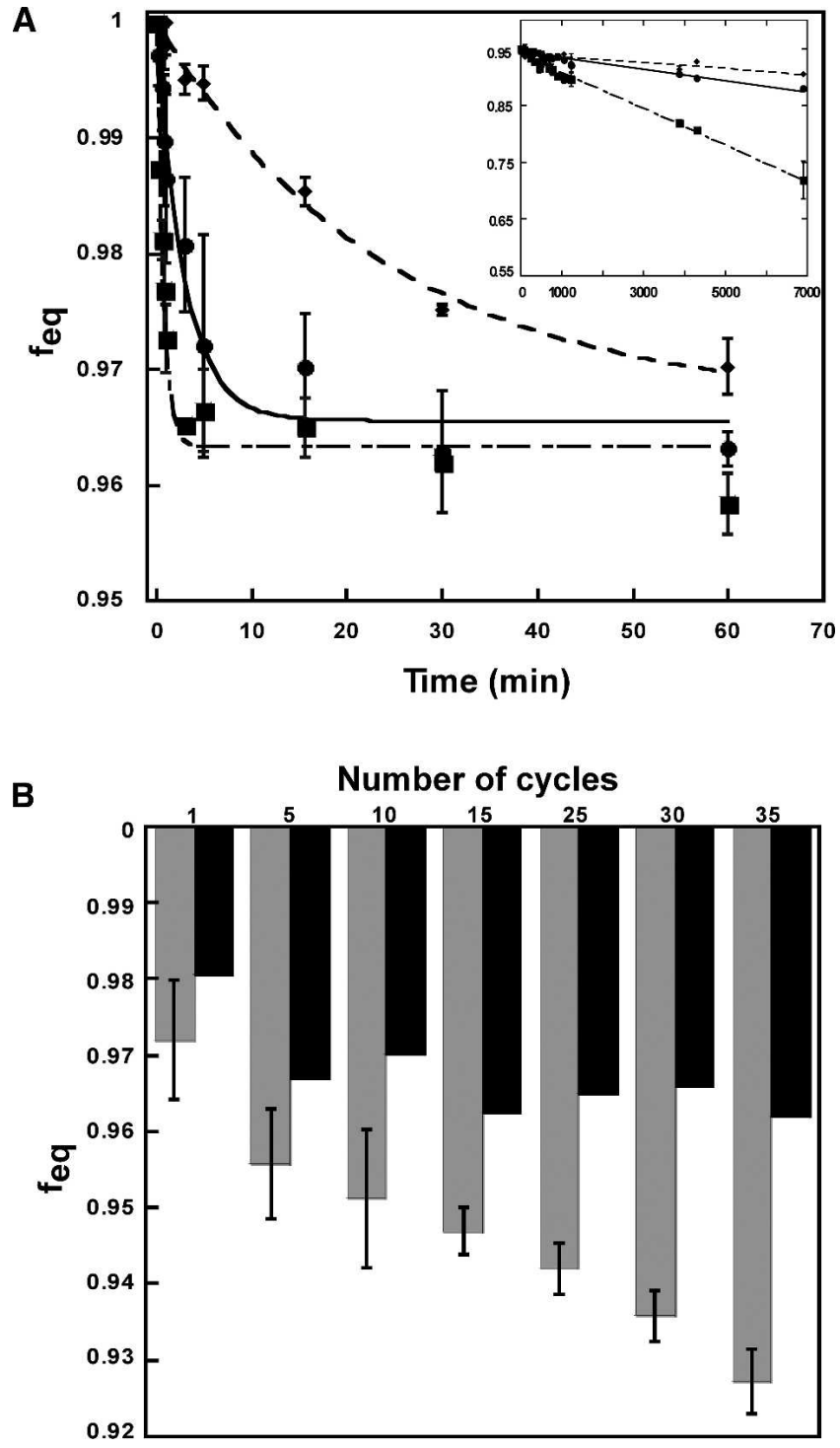

FIGURE 3. Biphasic cleavage kinetics of HH16(G17). (A) Average values determined from at least two independent experiments for initial phase of cleavage at $25^{\circ} \mathrm{C}$ in $10 \mathrm{mM} \mathrm{MgCl}_{2}$ and $(0) 100 \mathrm{mM}$ Hepes $\left(\mathrm{pH} 7.5 ; k_{\mathrm{obs}}=0.42 \pm 0.26 \mathrm{~min}^{-1}, f_{\mathrm{eq}}=0.97 \pm 0.04\right) ;(\mathbf{\square}) 100$ $\mathrm{mM}$ Tris $\mathrm{HCl}\left(\mathrm{pH} 8.1 ; k_{\mathrm{obs}}=1.6 \pm 0.4 \mathrm{~min}^{-1}, f_{\mathrm{eq}}=0.96 \pm 0.01\right)$; and (•) $100 \mathrm{mM}$ Mes $\left(\mathrm{pH} 6.5 ; k_{\mathrm{obs}}=0.031 \pm 0.003 \mathrm{~min}^{-1}, f_{\mathrm{eq}}=0.97 \pm\right.$ 0.01 ). Second slow phase of cleavage is shown in the inset. $(B) f_{\mathrm{eq}}$ obtained after successive cycles of heating to $65^{\circ} \mathrm{C}$ and cooling to $25^{\circ} \mathrm{C}$ shown in gray bars; black bar is control that was not heated to $65^{\circ} \mathrm{C}$ but held at $25^{\circ} \mathrm{C}$ for duration with aliquots removed at the end of cycles marked.

the rate of uncatalyzed cleavage of RNA. Versions of HH16 containing the G3C8 double mutant cleave > 1000-fold faster than either of the single mutants and, depending on the identity of the residue at position 17 , can have $k_{\mathrm{obs}}$ values within 90-fold of the native HH16. A3U8 and U3A8 substitutions can also partially support cleavage. This experiment strongly supports the notion that the C3-G8 pair also forms when HH16 adopts a catalytically active conformation that presumably resembles the structure of the catalytic core of the Schistosoma hammerhead.

NMR experiments performed on several minimal hammerheads indicate that while their catalytic cores are somewhat disordered, they clearly contain the sheared G8-A13 and A9-G12 base pairs that are part of domain 2 of the X-ray structure of the minimal hammerhead (Heus and Pardi 1991; Amano 2006). Since we have shown here that C3 must pair with G8 to form the active conformation, it is clear that the majority of minimal hammerheads in solution are not in an active conformation. This affirms the proposal of Peracchi et al. $(1997,1998)$ that minimal hammerheads in solution are primarily in inactive conformations that occasionally adopt active conformations. Minimal hammerhead cleavage and ligation can thus be described by three equilibria: (1) the rapid isomerization between the multiple inactive conformations and the single active conformation of the uncleaved hammerhead described by the equilibrium constant $K_{u}$; (2) catalysis of the active hammerhead described by the "internal" equilibrium $K_{\text {int }}$ that is the ratio of the elemental forward cleavage $\left(k_{2}\right)$ and reverse ligation $\left(k_{-2}\right)$ rate constants; and (3) the rapid isomerization between the single active conformation of the cleaved hammerhead and the multiple inactive conformations described by the equilibrium constant $K_{c}$ (Fig. 5). The rates of exchange between active and inactive conformations associated with $K_{u}$ and $K_{c}$ are very fast and therefore undetectable by experiments that measure the comparatively slow rate of hammerhead catalysis. Intramolecular RNA isomerizations of comparable

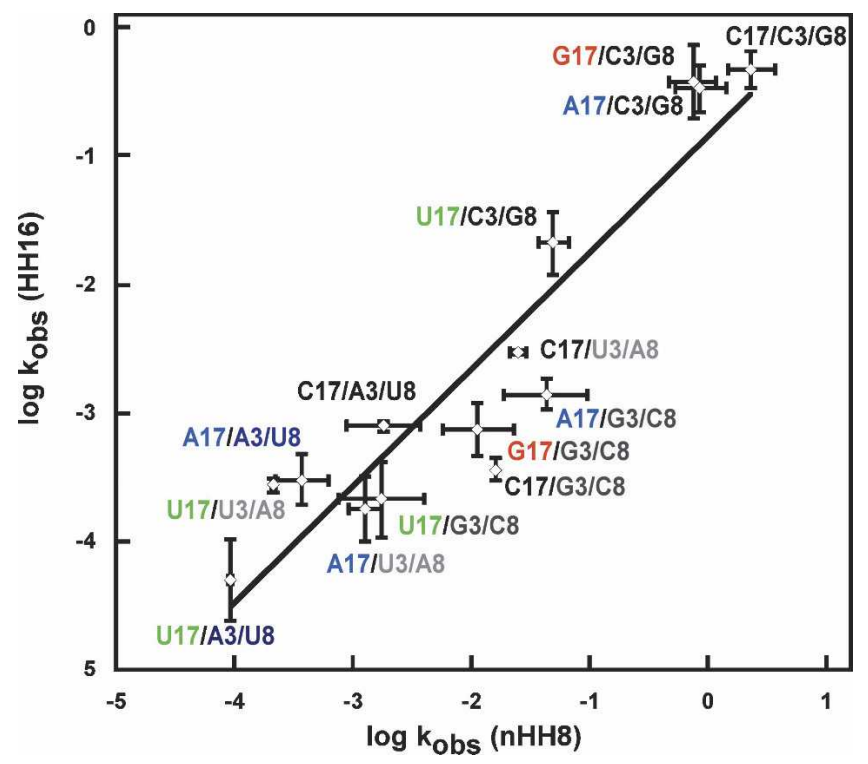

FIGURE 4. Correlation between $k_{\text {obs }}$ of mutations in minimal and extended hammerheads. $k_{\text {obs }}$ for HH16 mutations measured in $10 \mathrm{mM}$ $\mathrm{MgCl}_{2}, 100 \mathrm{~mm}$ Hepes (pH 7.5) at $25^{\circ} \mathrm{C}$ (Table 2) compared with $k_{\text {obs }}$ for same mutations in $\mathrm{nHH} 8$ measured in $1 \mathrm{mM} \mathrm{MgCl}_{2}, 50 \mathrm{mM}$ Mes ( $\mathrm{pH}$ 6) (Table 1). The best-fit least-squares line has a slope of 0.92 . 


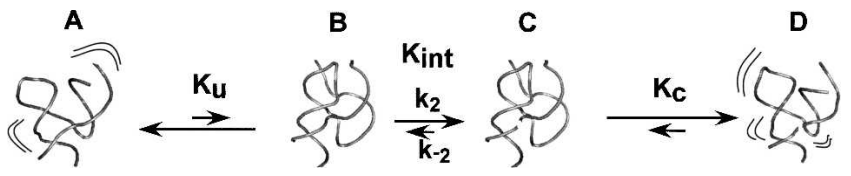

FIGURE 5. A model for the dynamic cleavage-ligation equilibria of minimal hammerheads. The majority of the uncleaved hammerheads consist of a dynamic mixture of structures $(A)$ that resemble the minimal hammerhead X-ray structure. A small fraction of the uncleaved molecules defined by $K_{u}$ transiently adopts an active conformation $(B)$ that resembles the Schistosoma core structure. The "internal" cleavage-ligation equilibrium $\left(K_{\text {int }}\right)$ is described the cleavage $\left(k_{2}\right)$ and ligation $\left(k_{-2}\right)$ rate constants. Finally, the cleaved active structure $(C)$ is in an equilibrium defined by $K_{c}$ with a mixture of cleaved inactive structures $(D)$ that also resemble the minimal hammerhead.

complexity in the hairpin ribozyme and the tetraloopreceptor complex are in the low millisecond time scale (Hodak et al. 2005; Wilson et al. 2005; Liu et al. 2007). For this description of the hammerhead reaction, the value of $k_{\text {obs }}$ can be expressed by

$$
k_{\mathrm{obs}}=\left(\frac{K_{u}}{1+K_{u}}\right) k_{2}+\left(\frac{1}{1+K_{c}}\right) k_{-2}
$$

and the value of $f_{\mathrm{eq}}$ can be expressed by

$$
f_{e q}=\frac{\left(\frac{1}{1+K_{c}}\right) k_{-2}}{k_{\mathrm{obs}}} .
$$

In the absence of independent measurements of $K_{u}$ and $K_{c}$, it is not possible to estimate their values unless additional assumptions are made. If we assume that the $k_{\text {obs }}=470 \mathrm{~min}^{-1}$ and $f_{\text {eq }}=0.05$ determined for nHH8 in 10 $\mathrm{mM} \mathrm{MgCl} 2$ (pH 7.5) (I. Shepotinovskaya, unpubl.) reflects an active hammerhead in both the uncleaved and cleaved forms $\left(K_{u} \gg 1, K_{c} \ll 1\right)$, then $k_{\mathrm{obs}}=k_{2}+k_{-2}$ and $f_{\mathrm{eq}}=k_{-2} /$ $\left(k_{2}+k_{-2}\right)$. This gives $k_{2}=477 \mathrm{~min}^{-1}$ and $k_{2}=23 \mathrm{~min}^{-1}$. Since HH16 shows $k_{\mathrm{obs}}=0.95 \mathrm{~min}^{-1}$ and $f_{\mathrm{eq}}=0.008$ in the same buffer, we can calculate $K_{u}=0.002$ and $K_{c}=3000$. In other words, the uncleaved HH16 only adopts the active conformation $\sim 0.2 \%$ of the time and, once cleaved, is only in the active conformation $\sim 0.03 \%$ of the time. The fact that $1 / \mathrm{K}_{\mathrm{c}}$ is smaller than $\mathrm{K}_{\mathrm{u}}$ reflects the fact that the $f_{\mathrm{eq}}=$ 0.008 for HH16 is less than the $f_{\mathrm{eq}}=0.05$ for $\mathrm{nHH} 8$ and indicates that the cleaved form of HH16 adopts a larger fraction of inactive conformations than the uncleaved form. This is consistent with the idea that the cleaved hammerhead is more flexible than the uncleaved because of the break in the phosphodiester bond. A similar conclusion was reached by comparing the properties of hammerheads containing a crosslink between helices 1 and 2 (StageZimmermann and Uhlenbeck 2001; Blount and Uhlenbeck 2002). However, it is important to point out that the assumption that both the cleaved and uncleaved forms of
nHH8 are in a fully active conformation may not be correct. In addition, although the cores of $\mathrm{nHH} 8$ and HH16 are identical, subtle differences in structures of the helices could lead to different $k_{2}$ or $k_{-2}$ values. If either of these possibilities are the case, the fractions of active HH16 molecules estimated above would be in error.

Since the rapid conformational isomerizations are such an important component in describing HH16 cleavage, they are likely to also contribute to the variability in $k_{\mathrm{obs}}$ for the HH16 mutations in Table 2. In all minimal hammerhead crystal structures, G8 pairs with A13, and in several of them, C3 pairs with C17 (Pley et al. 1994; Scott et al. 1995, 1996; Murray et al. 2000). Since these structures represent inactive conformations, mutations that stabilize these pairs would reduce HH16 activity while mutations that destabilize these pairs could increase HH16 activity. Thus, the poor activity for all A3U8 derivatives of HH16 may reflect the fact that a U8-A13 pair is more effective than the native G8-A13 pair in stabilizing domain II and thus maintaining the inactive conformation and decreasing $K_{u}$ even further. Similarly, as has previously been discussed (Baidya and Uhlenbeck 1997; Simorre et al. 1998), the slower $k_{\text {obs }}$ for the G17 and U17 derivatives of HH16 may partially reflect their more stable paring with C3 than with $\mathrm{C} 17$ or A17. Since we now know that C3 must pair with G8 for activity, any interaction that sequesters C3 would reduce cleavage.

The observed "synergistic" dependence of the activity of different 3-8 pairs upon the identity of position 17 in HH16 probably also reflects the relative stabilities of inactive and active conformations. Thus, the reason why the G3C8 inversion mutant has relatively low $k_{\mathrm{obs}}$ when $\mathrm{C} 17$ is present is because the transient formation of a stable G3-C17 pair effectively competes with the formation of the G3-C8 pair. The G3C8 inversion mutant is relatively more active when either U17, A17, or G17 is present, since the alternative G3-U17, G3-A17, or G3-G17 pairs are weaker and thus do not compete as well. Similarly, the exceptionally poor activity of HH16 containing A3U8 U17 may be the result of two alternative base pairs, A3-U17 and U8A13, which prevent formation of the A3-U8 pair. In other words, to properly interpret the effect of a HH16 mutation on $k_{\mathrm{obs}}$, it is critical to consider its effect on the conformational isomerizations as well as the cleavage step. Since the structures of minimal hammerheads can be considered to be representative of a set of inactive conformations and the catalytic core of the Schistosoma hammerhead is representative of a more active conformation, it is clear that both structures are critical to our understanding of minimal hammerhead function.

It is striking that the differences in $k_{\mathrm{obs}}$ for different $\mathrm{N} 17$ mutations and the synergies between N17 and the identity of the 3-8 bp are also observed for nHH8. Indeed, as shown in Figure 4, the magnitude of the effects of the mutations in $\mathrm{nHH} 8$ is quite similar to those seen in HH16. These results cannot be easily explained solely in terms of 
the Schistosoma crystal structure. While the somewhat slower $k_{\text {obs }}$ for the A17 and G17 versions of nHH8 could potentially be explained by somewhat worse fit of the purine rings into the position of $\mathrm{C} 17$, the very poor cleavage of $\mathrm{nHH} 8$ (U17) is hard to understand since U17 could also make the single hydrogen bond between its two oxygen and the amino group of A13 that is also observed for C17. The Schistosoma structure also does not easily explain how the identity of N17 would influence the effect of different 3-8 bp substitutions since N17 is 11-20 $\AA$ away from the 3-8 bp.

A better way to rationalize the varying effects of 3-8 bp substitution in different $\mathrm{N} 17$ backgrounds for $\mathrm{nHH} 8$ is to propose that many of the $\mathrm{nHH} 8$ mutations are also in rapid exchange with inactive conformations that resemble the minimal hammerhead in the same way as was proposed for HH16 in Figure 5. Just as discussed above for HH16 mutations, the slower $k_{\text {obs }}$ values for the $\mathrm{nHH} 8$ mutations can be understood by the fact that they stabilize the inactive minimal conformation by forming stable pairing interactions between N3 and N17 or between N8 and N13 that compete with the C3-G8 pair required for activity. For example, the G3C8 mutation in $\mathrm{nHH} 8$, which could make a stable G3-C17 pair in the minimal hammerhead structure, has a $k_{\text {obs }}=0.017 \mathrm{~min}^{-1}$ and a $f_{\text {eq }}=0.16$. If we assume that cleaved and uncleaved nHH8 are also in fully active conformations in the $1 \mathrm{mM} \mathrm{MgCl}_{2}$ ( $\mathrm{pH}$ 6.0) buffer, then its $k_{\text {obs }}=2.5 \mathrm{~min}^{-1}$ and $f_{\text {eq }}=0.05$ means that $k_{2}=2.375$ and $k_{-2}=0.125$. One can then calculate $K_{u}=0.006$ and $K_{c}=45$ for the G3C8 mutation. This would imply that only $0.6 \%$ of the uncleaved and $2 \%$ of the cleaved G3C8 hammerheads are in an active conformation. Since these estimates rely on the unproven assumption that nHH8 is fully active, they are mostly useful for illustrating that the changes in $k_{\mathrm{obs}}$ and $f_{\mathrm{eq}}$ reflect independent properties of each mutation. A reduced $k_{\text {obs }}$ indicates an increased population of inactive conformations compared with wild type. However, since the expression for $f_{\text {eq }}$ contains both $K_{u}$ and $K_{c}, f_{\text {eq }}$ can either increase or decrease depending upon the amount that the mutation alters each isomerization relative to wild type. It is interesting that for most of the nHH8 mutations, $f_{\text {eq }}$ is greater than the wild-type value of 0.05 , meaning that the proportion of uncleaved active molecules is reduced by more than the cleaved ones. In those cases where $f_{\text {eq }}$ is less than 0.05 , the opposite may be true, but one cannot rule out the possibility that the mutation results in trapping a fraction of the molecules in a state that never can reach an active conformation during the time course of the experiments. Further experiments measuring the corresponding cleavage reaction would help to resolve this point for these mutants.

If the $k_{\text {obs }}$ and $f_{\text {eq }}$ values of mutants of nHH8 can be explained by the dynamic equilibrium between multiple inactive forms and a single active form, it is possible that nHH8 itself may not always be in the active configuration.
This would mean that the $k_{\text {obs }}$ of nHH8 may not simply equal to $k_{2}+k_{-2}$, but could still contain a contribution from one or both isomerization equilibria. For example, it is known that the $k_{\text {obs }}$ of extended hammerheads increase with magnesium ion concentration, often without evidence of saturation (Canny et al. 2004; Nelson et al. 2005). While the reason for this is not well understood, it is possible that the increase could partially be due to one or more magnesium ions further stabilizing the active conformations. Since hammerhead activity will require positioning of catalytic functional groups and possible catalytic cations prior to cleavage, any interaction adding stability to pretransition state structures will increase the rate of catalysis. It is possible that the loop-bulge or loop-loop tertiary elements could have no direct role in the catalytic mechanism but simply increase the population of molecules with the requisite energy to reach the transition state (Rueda et al. 2003). This would explain why the tertiary elements are not phylogenetically conserved (Flores et al. 2001) and can be replaced by other stabilizing tertiary elements uncovered by in vitro selection experiments (Saksmerprome et al. 2004). Indeed, the tertiary structural elements of different natural hammerheads may have evolved to have values of $K_{u}$ and $K_{c}$ that adjust $k_{\mathrm{obs}}$ and/or $f_{\mathrm{eq}}$ to the value it needs for its physiological function. Thus, rapid conformational switching between active and inactive states could be a critical property in the evolution of hammerheads.

\section{MATERIALS AND METHODS}

\section{RNA oligonucleotides}

HH16 and the three double-mutant ribozyme strands were transcribed using T7 RNA polymerase (Milligan and Uhlenbeck 1989) from double-stranded DNA made by extending two overlapping synthetic oligonucleotides with Taq DNA polymerase. nHH8 and the three double-mutant hammerheads were transcribed in a similar fashion and allowed to cleave in the in vitro transcription reaction (Nelson et al. 2005). Transcription products were gel purified on $10 \%(\mathrm{w} / \mathrm{v})$ polyacrylamide gels and eluted overnight at $4^{\circ} \mathrm{C}$ in $0.5 \mathrm{M} \mathrm{NaOAc}$ and $1 \mathrm{mM}$ EDTA (pH 5.5), ethanol precipitated, and resuspended in water. The G3 and C8 single point mutants of $\mathrm{nHH} 8$ and $\mathrm{HH} 16$ and the substrate strands for the HH16 reaction (5'-GGGAACGUNGUCGUCGC, underlined nucleotide $\mathrm{N} 17=\mathrm{C}, \mathrm{A}, \mathrm{U}$, or $\mathrm{G}$ ) were purchased from Dharmacon, deblocked, and purified as described above. HH16 substrate strands were $5^{\prime}$ end-labeled using $\left[\gamma^{-{ }^{32}} \mathrm{P}\right]$-ATP $(\sim 6000$ $\mathrm{Ci} / \mathrm{mmol}$ ) and $\mathrm{T} 4$ polynucleotide kinase. The reactions were then passed through G-25 spin columns (Amersham Biosciences) to remove excess $\left[\gamma_{-}{ }^{32} \mathrm{P}\right]$-ATP and exchange the buffer into water. The cyclic phosphate substrates (GGGAACGUN $>p ; N>p=C>p$, $\mathrm{A}>\mathrm{p}, \mathrm{U}>\mathrm{p}$, or $\mathrm{G}>\mathrm{p}$ ) required for $\mathrm{nHH} 8$ ligation reactions were prepared by mixing the corresponding labeled HH16 substrate with $\mathrm{HH} 16$ ribozyme $(\mathrm{pH} 7.5)$ and $10 \mathrm{mM} \mathrm{MgCl}_{2}$ and were thermocycled as described (Nelson et al. 2005). The reactions were then passed through G-25 spin columns (Amersham Biosciences) to exchange buffer with water. 


\section{Rate measurements}

Cleavage reactions of wild-type and double-mutant HH16 ribozymes with $17 \mathrm{mer}$ substrates were carried out essentially as previously described (Hertel et al. 1994, 1996; Stage-Zimmermann and Uhlenbeck 1998). Reaction mixtures containing saturating $(2 \mu \mathrm{M})$ ribozyme were mixed with trace $(<5 \mathrm{nM})\left[5^{\prime}-^{32} \mathrm{P}\right]$-labeled substrate in $100 \mathrm{mM}$ Hepes ( $\mathrm{pH} 7.5$ ), heated to $95^{\circ} \mathrm{C}$ for $2 \mathrm{~min}$, and then allowed to slow cool to $40^{\circ} \mathrm{C}$ over $1 \mathrm{~h}$ to allow annealing. Reactions were then spun down and equilibrated for $10 \mathrm{~min}$ at $25^{\circ} \mathrm{C}$. Two-microliter aliquots were initiated with $20 \mu \mathrm{L}$ of 100 $\mathrm{mM}$ Hepes ( $\mathrm{pH} 7.5)$ and $20 \mathrm{mM} \mathrm{MgCl}$. Time points $(3 \mu \mathrm{L})$ were quenched in $15 \mu \mathrm{L}$ of stop solution (50 mM EDTA, $7 \mathrm{M}$ Urea, $<0.02 \%$ dyes) and held on ice (or frozen). Reactions were fractionated on $20 \%(\mathrm{w} / \mathrm{v})$ denaturing PAGE, and products were detected with a Molecular Dynamics Storm Phosphoimager (Amersham Biosciences) and quantified using ImageQuant (Amersham Biosciences). The data were fit by a single exponential to a $k_{\text {obs }}$ and $\mathrm{a} \mathrm{f}_{\mathrm{eq}}$, the fraction of full-length molecules at equilibrium, as described previously (Stage-Zimmermann and Uhlenbeck 1998). For the five mutants that did not reach completion during the time course of the experiment, it was assumed that $f_{\text {eq }}=0.30$, which is the average of $f_{\text {eq }}$ values obtained for the other mutants. An alternate approach to estimate $f_{\text {eq }}$ for these five very slow mutants was to determine the fraction of full-length remaining after $14 \mathrm{~d}$ of incubation. This value was consistently within \pm 0.1 of 0.3 . Since a \pm 0.1 error in $f_{\text {eq }}$ would lead to a $\pm 20 \%$ error in the corresponding $k_{\mathrm{obs}}$, the errors on $k_{\mathrm{obs}}$ for these six mutants may be somewhat greater than the standard deviations suggest.

For thermocycling experiments on $\mathrm{HH} 16(\mathrm{G} 17)$, cleavage reactions were initiated in $10 \mathrm{mM} \mathrm{MgCl}_{2}, 100 \mathrm{mM}$ Hepes $(\mathrm{pH} 7.5)$ at $25^{\circ} \mathrm{C}$ as described above. After $3 \mathrm{~min}$ at $25^{\circ} \mathrm{C}$, the temperature was increased for $1 \mathrm{~min}$ to $65^{\circ} \mathrm{C}$. After taking an aliquot, the reaction was returned to $25^{\circ} \mathrm{C}$ to start the next cycle. A control reaction omitted the $65^{\circ} \mathrm{C}$ incubation. Aliquots were quenched in $5 \times$ stop solution and analyzed as above.

Cleavage kinetics for the G3 and C8 single point mutants of HH16 were performed in $100 \mathrm{mM}$ Tris- $\mathrm{HCl}(\mathrm{pH} \mathrm{8.1)}$ and 100 $\mathrm{mM} \mathrm{MgCl} 2$. In order to compare these rates to the values of $k_{\text {obs }}$ of the other mutants, a correction to account for the $\mathrm{pH}$ and $\mathrm{MgCl}_{2}$ ion differences was needed. Since the $\log$ of $k_{\text {obs }}$ is known to vary linearly with both $\mathrm{pH}$ (Hertel and Uhlenbeck 1995) and the log of the magnesium ion concentration (O'Rear et al. 2001), the $k_{\text {obs }}$ values for the single mutants were divided by a factor of 4 to account for the difference in $\mathrm{pH}$ and a factor of 10 to account for the difference in the magnesium ion concentration.

Ligation reactions of wild-type $\mathrm{nHH} 8$ and its mutants with the 9mer substrates containing the terminal 2',3' C, A, U, or G cyclic phosphate were carried out as described above except for variations in buffer conditions and annealing procedure: $2 \mu \mathrm{M}$ ribozyme was mixed with $<5 \mathrm{nM}\left[5^{\prime}-{ }^{32} \mathrm{P}\right]$-labeled substrate in $50 \mathrm{mM}$ Mes ( $\mathrm{pH} \mathrm{6.0)}$ ), heated to $95^{\circ} \mathrm{C}$ for $2 \mathrm{~min}$, placed on ice for 2-6 min, spun down, and equilibrated at $25^{\circ} \mathrm{C}$ for $10 \mathrm{~min} ; 20 \mu \mathrm{L}$ aliquots were then placed in a 96-well plate and reactions were initiated with $20 \mu \mathrm{L}$ of $50 \mathrm{mM}$ Mes (pH 6.0) and $2 \mathrm{mM} \mathrm{MgCl}_{2}$; and $3 \mu \mathrm{L}$ time points were quenched and analyzed in the same way as the HH16 reactions to give values of $f_{\mathrm{eq}}$ and $k_{\mathrm{obs}}$. The G3 and G8 single point mutants were performed in $50 \mathrm{mM}$ Hepes ( $\mathrm{pH} 7.5$ ) and $10 \mathrm{mM} \mathrm{MgCl}_{2}$. In order to compare these values to the $k_{\text {obs }}$ of the double mutants, a correction to account for the $\mathrm{pH}$ and $\mathrm{MgCl}_{2}$ differences was needed. Again, since the log of $k_{\mathrm{obs}}$ for $\mathrm{nHH} 8$ is known to vary linearly with $\mathrm{pH}$ and with the log of magnesium ion concentration with a slope of two (I. Shepotinovskaya, unpubl.), $k_{\text {obs }}$ was divided by 32 to account for the difference in $\mathrm{pH}$ and by 100 to account for the difference in magnesium ion concentration.

\section{ACKNOWLEDGMENTS}

The project described above was supported by R01GM36944-22 from the National Institutes of Health, and 1C06RR01885001 from the National Center for Research Resources (NCRR), a component of the National Institutes of Health (NIH). Its contents are solely the responsibility of the authors and do not necessarily represent the official views of NCRR or NIH.

Received July 3, 2007; accepted September 21, 2007.

\section{REFERENCES}

Amano, M. 2006. NMR studes of the effect of GA-AG base pairs to the active conformation of the hammerhead ribozyme. Nucleic Acids Symp. Ser. 50: 43-44.

Baidya, N. and Uhlenbeck, O.C. 1997. A kinetic and thermodynamic analysis of cleavage site mutations in the hammerhead ribozyme. Biochemistry 36: 1108-1114.

Baidya, N., Ammons, G.E., Matulic-Adamic, J., Karpeisky, A.M., Beigelman, L., and Uhlenbeck, O.C. 1997. Functional groups on the cleavage site pyrimidine nucleotide are required for stabilization of the hammerhead transition state. RNA 3: 11351142.

Blount, K.F. and Uhlenbeck, O.C. 2002. Internal equilibrium of the hammerhead ribozyme is altered by the length of certain covalent crosslinks. Biochemistry 41: 6834-6841.

Blount, K.F. and Uhlenbeck, O.C. 2005. The structure-function dilemma of the hammerhead ribozyme. Annu. Rev. Biophys. Biomol. Struct. 34: 415-440.

Buzayan, J.M., Hampel, A., and Bruening, G. 1986. Nucleotide sequence and newly formed phosphodiester bond of spontaneously ligated satellite tobacco ringspot virus RNA. Nucleic Acids Res. 14: 9729-9743. doi: 10.1093/nar/14.24.9729.

Canny, M.D., Jucker, F.M., Kellogg, E., Khvorova, A., Jayasena, S.D., and Pardi, A. 2004. Fast cleavage kinetics of a natural hammerhead ribozyme. J. Am. Chem. Soc. 126: 10848-10849.

Canny, M.D., Jucker, F.M., and Pardi, A. 2007. Efficient ligation of the Schistosoma hammerhead ribozyme. Biochemistry 46: 3826-3834.

Carbonell, A., De la Pena, M., Flores, R., and Gago, S. 2006. Effects of the trinucleotide preceding the self-cleavage site on eggplant latent viroid hammerheads: Differences in co- and post-transcriptional self-cleavage may explain the lack of trinucleotide AUC in most natural hammerheads. Nucleic Acids Res. 34: 5613-5622. doi: 10.1093/nar/gkl717.

De la Pena, M., Gago, S., and Flores, R. 2003. Peripheral regions of natural hammerhead ribozymes greatly increase their self-cleavage activity. EMBO J. 22: 5561-5570.

Eckstein, F., Kore, A.R., and Nakamaye, K.L. 2001. In vitro selection of hammerhead ribozyme sequence variants. ChemBioChem 2: 629-635.

Flores, R., Hernandez, C., de la Pena, M., Vera, A., and Daros, J.A. 2001. Hammerhead ribozyme structure and function in plant RNA replication. Methods Enzymol. 341: 540-552.

Forster, A.C. and Symons, R.H. 1987a. Self-cleavage of plus and minus RNAs of a virusoid and a structural model for the active sites. Cell 49: $211-220$. 
Forster, A.C. and Symons, R.H. 1987b. Self-cleavage of virusoid RNA is performed by the proposed 55-nucleotide active site. Cell 50: $9-16$.

Garrett, T.A., Pabâon-Peäna, L.M., Gokaldas, N., and Epstein, L.M. 1996. Novel requirements in peripheral structures of the extended satellite 2 hammerhead. RNA 2: 699-706.

Herschlag, D., Khosla, M., Tsuchihashi, Z., and Karpel, R.L. 1994. An RNA chaperone activity of non-specific RNA binding proteins in hammerhead ribozyme catalysis. EMBO J. 13: 2913-2924 [erratum 13: 3926].

Hertel, K.J. and Uhlenbeck, O.C. 1995. The internal equilibrium of the hammerhead ribozyme reaction. Biochemistry 34: 1744-1749.

Hertel, K.J., Herschlag, D., and Uhlenbeck, O.C. 1994. A kinetic and thermodynamic framework for the hammerhead ribozyme reaction. Biochemistry 33: 3374-3385.

Hertel, K.J., Herschlag, D., and Uhlenbeck, O.C. 1996. Specificity of hammerhead ribozyme cleavage. EMBO J. 15: 3751-3757.

Hertel, K.J., Peracchi, A., Uhlenbeck, O.C., and Herschlag, D. 1997. Use of intrinsic binding energy for catalysis by an RNA enzyme. Proc. Natl. Acad. Sci. 94: 8497-8502.

Heus, H.A. and Pardi, A. 1991. Nuclear magnetic resonance studies of the hammerhead ribozyme domain. Secondary structure formation and magnesium ion dependence. J. Mol. Biol. 217: $113-124$.

Hodak, J.H., Downey, C.D., Fiore, J.L., Pardi, A., and Nesbitt, D.J. 2005. Docking kinetics and equilibrium of a GAAA tetraloopreceptor motif probed by single-molecule FRET. Proc. Natl. Acad. Sci. 102: 10505-10510 [erratum 13: 13351].

Hutchins, C.J., Rathjen, P.D., Forster, A.C., and Symons, R.H. 1986. Self-cleavage of plus and minus RNA transcripts of avocado sunblotch viroid. Nucleic Acids Res. 14: 3627-3640. doi: 10.1093/ nar/14.9.3627.

Khvorova, A., Lescoute, A., Westhof, E., and Jayasena, S.D. 2003. Sequence elements outside the hammerhead ribozyme catalytic core enable intracellular activity. Nat. Struct. Biol. 10: 708-712.

Koizumi, M. and Ohtsuka, E. 1991. Effects of phosphorothioate and 2 -amino groups in hammerhead ribozymes on cleavage rates and $\mathrm{Mg}^{2+}$ binding. Biochemistry 30: 5145-5150.

Koizumi, M., Iwai, S., and Ohtsuka, E. 1988a. Cleavage of specific sites of Rna by designed ribozymes. FEBS Lett. 239: 285-288.

Koizumi, M., Iwai, S., and Ohtsuka, E. 1988b. Construction of a series of several self-cleaving Rna duplexes using synthetic 21-mers. FEBS Lett. 228: 228-230.

Kore, A.R., Vaish, N.K., Morris, J.A., and Eckstein, F. 2000. In vitro evolution of the hammerhead ribozyme to a purine-specific ribozyme using mutagenic PCR with two nucleotide analogues. J. Mol. Biol. 301: 1113-1121.

Li, Y.F. and Breaker, R.R. 1999. Kinetics of RNA degradation by specific base catalysis of transesterification involving the $2^{\prime}$ hydroxyl group. J. Am. Chem. Soc. 121: 5364-5372.

Liu, S., Bokinsky, G., Walter, N., and Zhuang, X. 2007. Dissecting the multistep reaction pathway of an RNA enzyme by singlemolecule kinetic "fingerprinting." Proc. Natl. Acad. Sci. 104: 12634-12639.

Martick, M. and Scott, W.G. 2006. Tertiary contacts distant from the active site prime a ribozyme for catalysis. Cell 126: 309-320.

McKay, D.B. 1996. Structure and function of the hammerhead ribozyme: An unfinished story. RNA 2: 395-403.

Milligan, J.F. and Uhlenbeck, O.C. 1989. Synthesis of small RNAs using T7 RNA polymerase. Methods Enzymol. 180: 51-62.

Murray, J.B., Adams, C.J., Arnold, J.R., and Stockley, P.G. 1995. The roles of the conserved pyrimidine bases in hammerhead ribozyme catalysis: Evidence for a magnesium ion-binding site. Biochem. J. 311: 487-494.

Murray, J.B., Terwey, D.P., Maloney, L., Karpeisky, A., Usman, N., Beigelman, L., and Scott, W.G. 1998. The structural basis of hammerhead ribozyme self-cleavage. Cell 92: 665-673.

Murray, J.B., Szoke, H., Szoke, A., and Scott, W.G. 2000. Capture and visualization of a catalytic RNA enzyme-product complex using crystal lattice trapping and X-ray holographic reconstruction. Mol. Cell 5: 279-287.

Nelson, J.A., Shepotinovskaya, I., and Uhlenbeck, O.C. 2005. Hammerheads derived from sTRSV show enhanced cleavage and ligation rate constants. Biochemistry 44: 14577-14585.

O'Rear, J.L., Wang, S., Feig, A.L., Beigelman, L., and Uhlenbeck, O.C. 2001. Comparison of the hammerhead cleavage reactions stimulated by monovalent and divalent cations. RNA 7: 537-545.

Peracchi, A., Beigelman, L., Usman, N., and Herschlag, D. 1996. Rescue of abasic hammerhead ribozymes by exogenous addition of specific bases. Proc. Natl. Acad. Sci. 93: 11522-11527.

Peracchi, A., Beigelman, L., Scott, E.C., Uhlenbeck, O.C., and Herschlag, D. 1997. Involvement of a specific metal ion in the transition of the hammerhead ribozyme to its catalytic conformation. J. Biol. Chem. 272: 26822-26826.

Peracchi, A., Karpeisky, A., Maloney, L., Beigelman, L., and Herschlag, D. 1998. A core folding model for catalysis by the hammerhead ribozyme accounts for its extraordinary sensitivity to abasic mutations. Biochemistry 37: 14765-14775.

Pley, H.W., Flaherty, K.M., and McKay, D.B. 1994. Threedimensional structure of a hammerhead ribozyme. Nature 372: 68-74.

Przybilski, R. and Hammann, C. 2007. The tolerance to exchanges of the Watson-Crick base pair in the hammerhead ribozyme core is determined by surrounding elements. RNA 13: 16251630.

Roychowdhury-Saha, M. and Burke, D.H. 2006. Extraordinary rates of transition metal ion-mediated ribozyme catalysis. RNA 12: 1846-1852.

Rueda, D., Wick, K., McDowell, S.E., and Walter, N.G. 2003. Diffusely bound $\mathrm{Mg}^{2+}$ ions slightly reorient stems I and II of the hammerhead ribozyme to increase the probability of formation of the catalytic core. Biochemistry 42: 9924-9936.

Ruffner, D.E., Stormo, G.D., and Uhlenbeck, O.C. 1990. Sequence requirements of the hammerhead RNA self-cleavage reaction. Biochemistry 29: 10695-10702.

Saksmerprome, V., Roychowdhury-Saha, M., Jayasena, S., Khvorova, A., and Burke, D.H. 2004. Artificial tertiary motifs stabilize trans-cleaving hammerhead ribozymes under conditions of submillimolar divalent ions and high temperatures. RNA 10: 1916-1924.

Scott, W.G., Finch, J.T., and Klug, A. 1995. The crystal structure of an all-RNA hammerhead ribozyme: A proposed mechanism for RNA catalytic cleavage. Cell 81: 991-1002.

Scott, W.G., Murray, J.B., Arnold, J.R., Stoddard, B.L., and Klug, A. 1996. Capturing the structure of a catalytic RNA intermediate: The hammerhead ribozyme. Science 274: 2065-2069.

Simorre, J.P., Legault, P., Baidya, N., Uhlenbeck, O.C., Maloney, L., Wincott, F., Usman, N., Beigelman, L., and Pardi, A. 1998. Structural variation induced by different nucleotides at the cleavage site of the hammerhead ribozyme. Biochemistry 37: 4034-4044.

Slim, G. and Gait, M.J. 1991. Configurationally defined phosphorothioate-containing oligoribonucleotides in the study of the mechanism of cleavage of hammerhead ribozymes. Nucleic Acids Res. 19: 1183-1188. doi: 10.1093/nar/19.6.1183.

Soukup, G.A. and Breaker, R.R. 1999. Relationship between internucleotide linkage geometry and the stability of RNA. RNA 5: 13081325.

Stage-Zimmermann, T.K. and Uhlenbeck, O.C. 1998. Hammerhead ribozyme kinetics. RNA 4: 875-889.

Stage-Zimmermann, T.K. and Uhlenbeck, O.C. 2001. A covalent crosslink converts the hammerhead ribozyme from a ribonuclease to an RNA ligase. Nat. Struct. Biol. 8: 863-867.

Tuschl, T., Ng, M.M., Pieken, W., Benseler, F., and Eckstein, F. 1993. Importance of exocyclic base functional groups of central core guanosines for hammerhead ribozyme activity. Biochemistry 32: 11658-11668 [erratum 33: 848]. 
Uhlenbeck, O.C. 1987. A small catalytic oligoribonucleotide. Nature 328: 596-600.

Vaish, N.K., Heaton, P.A., Fedorova, O., and Eckstein, F. 1998. In vitro selection of a purine nucleotide-specific hammerheadlike ribozyme. Proc. Natl. Acad. Sci. 95: 2158-2162.

van Tol, H., Buzayan, J.M., Feldstein, P.A., Eckstein, F., and Bruening, G. 1990. Two autolytic processing reactions of a satellite RNA proceed with inversion of configuration. Nucleic Acids Res. 18: 1971-1975. doi: 10.1093/nar/18.8.1971.
Verma, S., Vaish, N.K., and Eckstein, F. 1997. Structure-function studies of the hammerhead ribozyme. Curr. Opin. Chem. Biol. 1: $532-536$.

Wang, S., Karbstein, K., Peracchi, A., Beigelman, L., and Herschlag, D. 1999. Identification of the hammerhead ribozyme metal ion binding site responsible for rescue of the deleterious effect of a cleavage site phosphorothioate. Biochemistry 38: 14363-14378.

Wilson, T.J., Nahas, M., Ha, T., and Lilley, D.M. 2005. Folding and catalysis of the hairpin ribozyme. Biochem. Soc. Trans. 33: 461-465. 

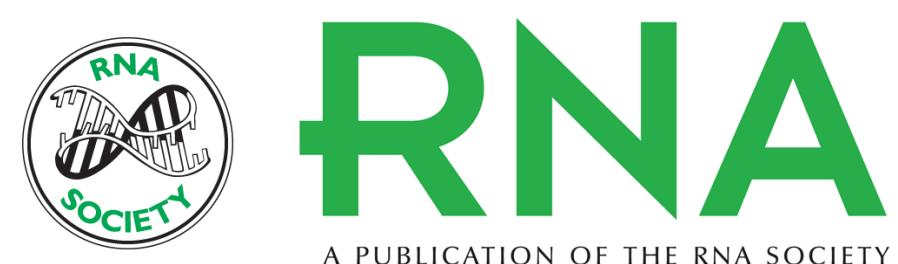

A PUBLICATION OF THE RNA SOCIETY

\section{Minimal and extended hammerheads utilize a similar dynamic reaction mechanism for catalysis}

Jennifer A. Nelson and Olke C. Uhlenbeck

RNA 2008 14: 43-54

References This article cites 61 articles, 16 of which can be accessed free at: http://rnajournal.cshlp.org/content/14/1/43.full.html\#ref-list-1

\section{License}

Email Alerting

Receive free email alerts when new articles cite this article - sign up in the box at the Service top right corner of the article or click here. 